Boston University School of Law Scholarly Commons at Boston University School of Law

Faculty Scholarship

$1-2016$

\title{
International Cooperation to Improve Access to and Sustain Effectiveness of Antimicrobials
}

\author{
Kevin Outterson \\ Boston University School of Law \\ Christine Ardal \\ University of Oslo \\ Steven Hoffman \\ University of Ottawa \\ Abdul Ghafur \\ Apollo Hospital \\ Mike Sharland \\ St. George's Hospital Medical School \\ See next page for additional authors
}

Follow this and additional works at: https://scholarship.law.bu.edu/faculty_scholarship

Part of the Health Law and Policy Commons

\section{Recommended Citation}

Kevin Outterson, Christine Ardal, Steven Hoffman, Abdul Ghafur, Mike Sharland, Nisha Ranganathan, Richard Smith, Anna Zorzet, Jennifer Cohn, Didier Pittet, Nils Daulaire, Chantal Morel, Zain Rizvi, Manica Balasegaram, Osman Dar, David Heymann, Alison Holmes, Luke Moore, Ramanan Laxminarayan, Marc Mendelson \& John-Arne Røttingen, International Cooperation to Improve Access to and Sustain Effectiveness of Antimicrobials, 387 The Lancet 296 (2016).

Available at: https://scholarship.law.bu.edu/faculty_scholarship/92

This Article is brought to you for free and open access by Scholarly Commons at Boston University School of Law. It has been accepted for inclusion in Faculty Scholarship by an authorized administrator of 


\section{Authors}

Kevin Outterson, Christine Ardal, Steven Hoffman, Abdul Ghafur, Mike Sharland, Nisha Ranganathan, Richard Smith, Anna Zorzet, Jennifer Cohn, Didier Pittet, Nils Daulaire, Chantal Morel, Zain Rizvi, Manica Balasegaram, Osman Dar, David Heymann, Alison Holmes, Luke Moore, Ramanan Laxminarayan, Marc Mendelson, and John-Arne Røttingen 


\title{
BU School of Law
}

\section{INTERNATIONAL COOPERATION TO IMPROVE ACCESS TO AND SUSTAIN EFFECTIVENESS OF ANTIMICROBIALS}

\author{
Boston University School of Law \\ Public Law \& Legal Theory Paper No. 16-16
}

Lancet 2016; 387: 296-307

January 16, 2016

This paper can be downloaded without charge at:

http://www.bu.edu/law/faculty-scholarship/working-paper-series/ 


\title{
(1) Antimicrobials: access and sustainable effectiveness 5
}

\section{International cooperation to improve access to and sustain effectiveness of antimicrobials}

\author{
Christine Årdal, Kevin Outterson, Steven J Hoffman, Abdul Ghafur, Mike Sharland, Nisha Ranganathan, Richard Smith, Anna Zorzet, \\ Jennifer Cohn, Didier Pittet, Nils Daulaire, Chantal Morel, Zain Rizvi, Manica Balasegaram, Osman A Dar, David L Heymann, Alison H Holmes, \\ Luke S P Moore, Ramanan Laxminarayan, Marc Mendelson, John-Arne Røttingen
}

Lancet 2016; 387: 296-307 Published Online November 18, 2015 http://dx.doi.org/10.1016/ S0140-6736(15)00470-5 This is the fifth in a Series of five papers about access to and sustainable effectiveness of antimicrobials

Norwegian Institute of Public Health, Oslo, Norway (C Årdal MBA, N Daulaire MD, Prof J-A Røttingen MD); School of Law, Boston University, Boston, MA, USA (Prof K Outterson JD); Chatham House Centre on Global Health Security, London, UK (Prof K Outterson, O A Dar FFPH, Prof D L Heymann MD); Global Strategy Lab, Faculty of Law,

Securing access to effective antimicrobials is one of the greatest challenges today. Until now, efforts to address this issue have been isolated and uncoordinated, with little focus on sustainable and international solutions. Global collective action is necessary to improve access to life-saving antimicrobials, conserving them, and ensuring continued innovation. Access, conservation, and innovation are beneficial when achieved independently, but much more effective and sustainable if implemented in concert within and across countries. WHO alone will not be able to drive these actions. It will require a multisector response (including the health, agriculture, and veterinary sectors), global coordination, and financing mechanisms with sufficient mandates, authority, resources, and power. Fortunately, securing access to effective antimicrobials has finally gained a place on the global political agenda, and we call on policy makers to develop, endorse, and finance new global institutional arrangements that can ensure robust implementation and bold collective action.

\section{Introduction}

This Lancet Series has argued that both inadequate access to antimicrobials and antimicrobial resistance are daunting threats to both human and animal health-ie, a One Health approach is necessary to address these issues. The most cost-effective and time-efficient method is to protect the usefulness and longevity of existing

Key messages

- Global collaboration is necessary to improve access to antimicrobials and sustain their effectiveness. Although this is well known and accepted, present collaborative efforts remain far too modest and poorly funded.

- Interlinked global collaboration is needed in the policy areas of universal access, responsible use, and innovation. Increasing innovation and global access without responsible use provisions might increase the emergence of resistance. Strengthened efforts towards responsible use could lead to smaller and less lucrative markets, thus dampening innovation and possibly impeding access. To avoid improper incentives to waste antimicrobials, payments for antimicrobials should be delinked from the volumes sold.

- WHO cannot successfully tackle this problem on its own. Because of the multisectoral nature of the problem-requiring action across the health, agriculture, and veterinary sectors-and the need to build new business models for antimicrobial innovation and use, multisectoral coordination under a One Health model is necessary to bring about action and real change.

- Global actions to address this challenge need to be a combination of quick wins and long-term efforts. For example, a few large markets could agree to restrict certain classes of antimicrobials only to human use while a formal global mechanism is being negotiated and adopted. This combination of short-term and long-term strategies needs to be taken for each policy area-namely, surveillance, universal access, infection prevention, responsible use, and innovation.

- Global coordination and financing mechanisms need to be improved. Two leading institutional options are a new UN-level coordinating body and an international treaty with strong implementation mechanisms.

antimicrobials, while continuing research into new vaccines, drugs, and related technologies, for much is still to be learnt about the mechanisms of infection and resistance. $^{2}$ The starting point for any concerted policy action should be to expand access to life-saving antimicrobials worldwide, recognising that some parts of the world still face issues of poor sanitation and inadequate access to antimicrobials. ${ }^{3}$ However, expansion of access needs to be linked to improved approaches for combating resistance. Evidence shows that many interventions can be effective at national levels, ${ }^{4}$ but their implementation also requires global vigilance and action.

Coordination across sectors is necessary to preserve antimicrobial effectiveness. Gains in combating resistance through health-care interventions might be undercut by prolific use in agricultural settings. Strong conservation efforts, although medically appropriate, might hamper the business case for innovation that leads to new therapies. Boosting access without stewardship measures could drive resistance. Thus, although many actions can be taken independently at the national and sectoral levels they will be more effective if coordinated globally across all relevant sectors and stakeholders. ${ }^{5}$

The complex policy challenges of improving access to and sustaining effectiveness of antimicrobials warrant interventions in several areas. This Lancet Series has used a framework spanning the breadth of policy goals needed. ${ }^{4}$ Improved surveillance and monitoring are crucial to obtain information on the present situation and progress. ${ }^{4}$ Universal access to antimicrobials needs to be a primary goal in all countries progressing towards universal health coverage. ${ }^{3}$ However, the need for antimicrobials can be lessened through improved infection control, and their use can become more appropriate by reducing misuse and overuse through 
interventions that decrease both supply and demand., ${ }^{3,4}$ Progress towards these goals will rely on raised awareness among the public and all relevant stakeholders (eg, policy makers and health-care personnel). ${ }^{4}$ Advances also need to build on an expanded knowledge base, through innovation and research and development (R\&D), to achieve an increased understanding of mechanisms and drivers of resistance, ${ }^{2}$ develop new technologies, ${ }^{3}$ and design, implement, and assess interventions. ${ }^{4}$ The control and reduction of resistance are public goods-ie, achievements in which all stand to benefit. However, with increasing antimicrobial resistance in low-income and middle-income countries (LMICs), ${ }^{1}$ these nations will struggle to finance the implementation of these policies, and financial assistance will be key to global success.

In this last paper of the Series, we analyse how countries and other stakeholders need to work together to achieve these key policy goals. We identify existing gaps in international cooperation, recommend actions to improve collaboration, and discuss how the resulting policies could be packaged for adoption and implementation.

\section{Strengthening international collaboration}

We reviewed all World Health Assembly resolutions and documentation related to antimicrobial resistance, in addition to related scientific literature published in 2012-15, to identify core high-level policy areas-namely, surveillance, universal access, responsible use, infection control, and innovation. Improved implementation across these policy areas is needed to ensure sustainable access to effective antimicrobials. Together with the other papers in this Series, ${ }^{1-4}$ we identified important gaps in international collaboration in each of the five policy areas (panel). However, the level of collaboration necessary to ensure success will differ from policy to policy. On the basis of the 5C Framework (figure), previously used to analyse human resources for health, we assessed the minimum level of collaboration needed for a policy to achieve its goal and the relevant international policies (table 1).

Some global policy objectives can be met by collaborative mechanisms that help to set common norms, principles, and goals. This is the lowest level of collaboration in the 5C Framework, one that is often effectively fulfilled by UN entities and exemplified by WHO's resolutions on antimicrobial resistance. ${ }^{1}$ However, higher levels of collaboration are necessary for other objectives. For example, another function of WHO is to facilitate communication, which includes sharing of information and data between countries-eg, dissemination of guidance and educational material on appropriate disease management and treatment regimens. ${ }^{3}$ Coordination is essential for effective global surveillance systems and for the uptake of adequate infection control procedures. ${ }^{3,4}$ Other objectives-eg, promotion of universal access, responsible use, and innovation-will need even higher levels of collaboration,
Panel: Gaps in international collaboration

- Surveillance-no global database exists for antimicrobial resistance or use, meaning that identification of surveillance gaps is difficult or impossible. No publicly available registry of laboratory capacity by country exists. Surveillance data are rarely recorded in real time or globally compatible in format.

- Infection control-a common repository for evidence of infection prevention measures is absent. Substantial financing and technical assistance is needed to help low-income and middle-income countries (LMICs) to implement evidence-based national infection prevention programmes.

- Universal access-no internationally agreed mechanisms exist to ensure affordability in LMICs. Financing to support improved access to antibiotics is restricted

- Responsible use in human beings - the framework to restrict marketing of antimicrobials has not been agreed. Capacities to enforce existing regulations are insufficient, and no internationally agreed quality measures for optimum prescribing exist.

- Responsible use in animals-no global mechanisms exist to reduce inappropriate use in animal husbandry or restrict specific classes to human use only. Europe is the only region that have banned the use of antibiotics in livestock and agriculture as growth promoters or for disease prevention.

- Innovation-existing incentives are not well aligned to responsible use policies. The bulk of these initiatives were not developed with the needs of LMICs in mind. The scale of these initiatives is insufficient to ensure the development of new antimicrobials, diagnostics, vaccines, or related technologies that target unmet medical needs.

including collaborative decisions and, at the highest level, collective action (figure). Such international collaboration is necessary to ensure the success of many policies that improve access to and sustain effectiveness of antimicrobials (table 1).

\section{Surveillance}

Two related issues of surveillance are collection and reporting of data, and strengthening of laboratory capacity. WHO first passed a resolution in 1998 urging Member States to develop surveillance systems for antimicrobial agents. ${ }^{7}$ Despite the WHO global strategy for containment of antimicrobial resistance (2001) and recurrent calls to improve these global surveillance efforts, little progress has been made in the past 15 years. ${ }^{8}$ Worryingly, the first antimicrobial resistance global report on surveillance (2014) of existing national systems showed that only 22 countries were able to report on all nine bacterial species of international concern. However, 114 of the 129 countries who reported their status obtained data for at least one species.
University of Ottawa, Ottawa, ON, Canada (S J Hoffman JD) Department of Global Health and Population, Harvard TH Chan School of Public Health, Harvard University, Boston, MA, USA (S) Hoffman, Prof J-A Røttingen); Apollo Hospital, Chennai, India (Prof A Ghafur MD); Pediatric Infectious Diseases Research Group, St George's University, London, UK

(M Sharland FRCPCH); Worldwide Antimalarial Resistance Network, Oxford, UK (N Ranganathan MRCP); Faculty of Public Health and Policy (Prof R Smith PhD), London School of Hygiene \& Tropical Medicine, London, UK (Prof D L Heymann); Uppsala University, Uppsala, Sweden (A Zorzet PhD); ReAct-Action on Antibiotic Resistance, Uppsala, Sweden (A Zorzet); Access Campaign, Médecins Sans Frontières, Geneva, Switzerland (J Cohn MD M Balasegaram MD); Division of Infectious Diseases, University of Pennsylvania, Philadelphia, PA, USA (J Cohn); Faculty of Medicine, University of Geneva Hospitals, Geneva, Switzerland (Prof D Pittet MD,

( Morel MSc); WHO

Collaborating Centre on Patient Safety, Geneva, Switzerland (Prof D Pittet); LSE Health, London School of Economics and Political Science, London, UK (C Morel); Yale Law School, Yale University, New Haven, CT, USA (Z Rizvi BHSc); Public Health England, London, UK (O A Dar, Prof D L Heymann); National Institute of Health Research Health Protection Research Unit in Healthcare Associated Infection and Antimicrobial Resistance, and Department of Infectious Diseases, Imperial College London, London, UK (Prof A H Holmes MD, LS P Moore MPH); Center for Disease Dynamics, Economics \& Policy, Washington, DC, USA (R Laxminarayan PhD); Princeton Environmental Institute, Princeton, NJ, USA (R Laxminarayan); Public Health Foundation of India, New Delhi, India (R Laxminarayan); Division of Infectious Diseases and HIV Medicine, Department of Medicine, University of Cape Town, Groote Schuur Hospital, 


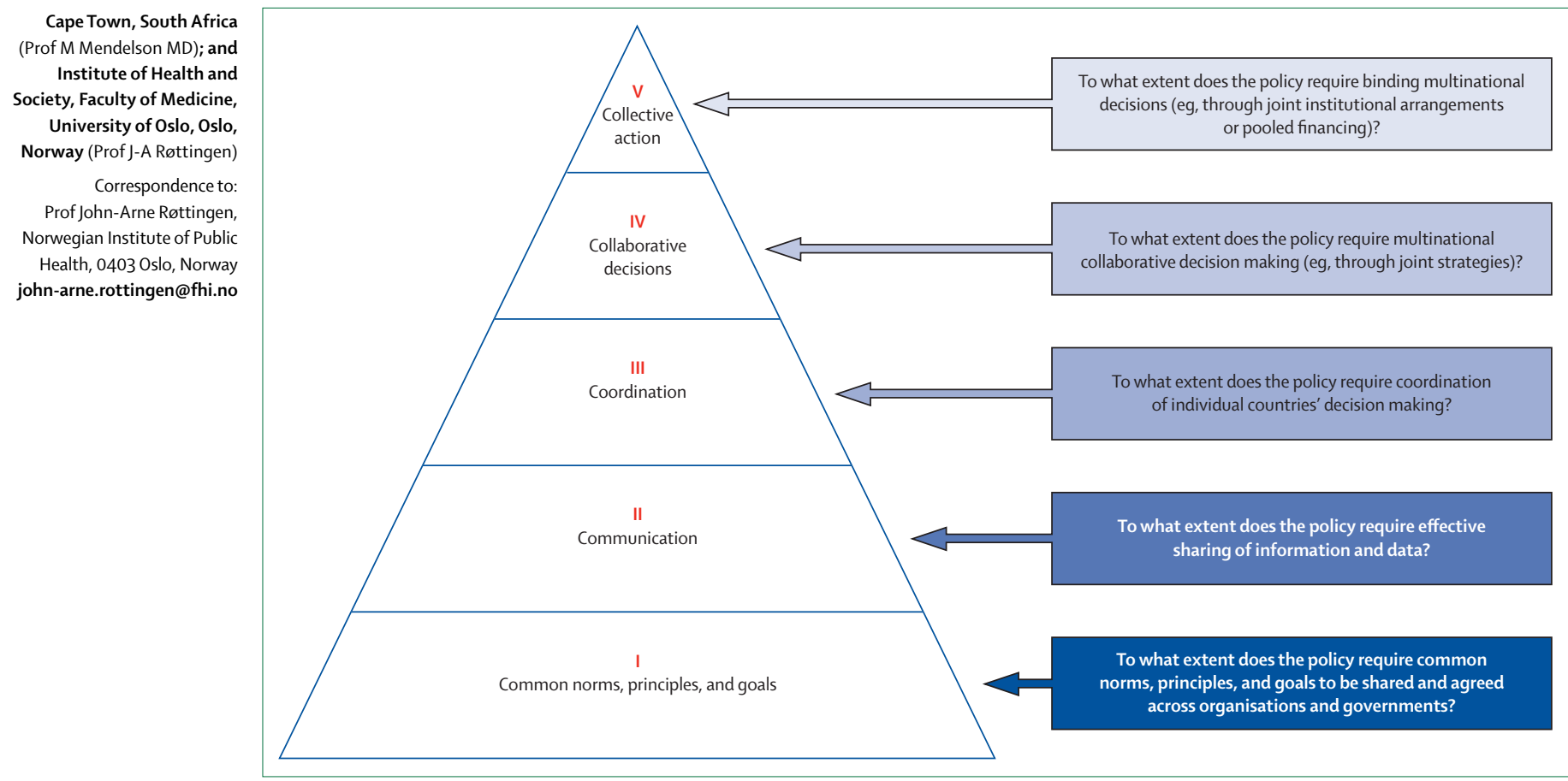

Figure: The 5 C Framework-assessment of minimum collaboration needed for a successful policy

This framework can be used to assess the minimum level of collaboration needed for a policy to deliver its stated goal. It is hierarchical-ie, level V (collective action) requires greater collaboration than level IV (collaborative decisions) and so on.

To comply with the International Health Regulations (IHR; 2005), each government is required to have access to laboratory services and obliged to report to WHO. ${ }^{10}$ At the WHO Executive Board Meeting in January, 2014, only 23 Member States were reported to be fully compliant with the IHR's laboratory requirements. ${ }^{11}$ This self-reporting shows that many Member States, across all income categories, are struggling with the laboratory capacities stipulated by the IHR. Since these capacities are more comprehensive than those necessary for antimicrobial resistance surveillance, the actual magnitude of inadequate laboratory capacity directly related to antimicrobial resistance is unknown at present. In 2011, three UN agencies-WHO, World Organisation for Animal Health (OIE), and the Food and Agriculture Organization (FAO)-jointly initiated several collaborative projects that aimed to strengthen laboratory capacity. These projects included capacity building for compliance with laboratory quality standards, the development of international networks, and laboratory twinning initiatives. ${ }^{12}$

A global surveillance system is essential to improve access to and sustain the effectiveness of antimicrobials. ${ }^{4}$ The communication of surveillance data can help to identify patterns of resistance and focus on necessary support. This is not a call for a new global super system but rather a coordinated effort to obtain data from present functioning systems, implement appropriate systems in countries without existing ones, report these data, and highlight the gaps annually. These data include the use of antimicrobials (in human beings and livestock, and for other agricultural purposes), the prevalence of antimicrobial resistance, and laboratory capacity, all by country, in a standard way so that valid comparisons can be made. This coordination will require cross-sectoral focus bridging the FAO, OIE, and WHO. To accurately report prevalence data, national and regional laboratory capacity has to be strengthened. Capacity-building plans, including technical and financial support, should be created for countries that are unable to report these data. As this function matures and as countries improve their reporting, interoperability and minimum data standards can be implemented.

\section{Infection control}

Many infection control collaborations are at work across the globe through local, national, regional, and international networks, as detailed by Dar and colleagues in this Lancet Series. ${ }^{4}$ However, many of these collaborations are underfunded. LMICs are lagging behind high-income countries, predominantly because of inadequate financial resources necessary for good infection control. ${ }^{13}$

National infection prevention programmes are the mandate of governments, but external supportive financing of these efforts in LMICs should continue. These efforts should be linked to surveillance data so that those countries reporting increasing resistance levels or inappropriate use can receive technical and financial assistance to reverse these trends. On a global basis, it might be more efficient to speed the adoption of basic 
Level of cooperation $-5 \mathrm{C}$ assessment

\section{Surveillance} surveillance data collection and reporting
Develop mechanisms for

Communication (level II)—surveillance information needs to be shared internationally. Efforts have already been attempted with common norms, principles, and goals. Each of the four WHO resolutions from 1998 to 2014 has urged Member States towards heightened surveillance.

Coordination (level III)-a global agreement on an international data collection mechanism is needed to ensure that countries are tracking key drug-bug combination data and using common standards. With a global system, countries that are yet to achieve fully developed monitoring systems can be rapidly identified and offered assistance. As this reporting process matures, interoperability and reporting standards will become important. Surveillance data will need to be centrally stored, analysed, and monitored for gaps. Data should have the potential to be aggregated to allow for meaningful analyses of resistance on a large scale, and a cross-sectoral focus bridging $\mathrm{FAO}, \mathrm{OIE}$, and WHO is necessary.

Build laboratory capacity and Coordination (level III)—-donors and governments need to jointly prioritise financing and technical capacity building to improve implement regionally national and regional laboratories. For countries without sufficient laboratory capacity, at a minimum, a plan should be developed and financed to offer either a national or a regional solution. WHO has been delivering on common norms, principles, and goals of best practices for laboratories and communicating these to Member States. Two of the four WHO resolutions urge Member States to improve laboratory capacity building. A higher level of collaboration is needed.

\section{Infection control}

Finance and generate evidence of infection prevention and control interventions

\section{Universal access}

Ensure that effective antimicrobials are equitably accessible

Communication (level II) - evidence of effective interventions is a global public good to be shared, summarised, and promoted to stakeholders and policy makers.

Coordination (level III) - LMICs might need financial assistance to implement sufficient interventions. Donors need to jointly prioritise the financing of effective infection prevention measures, such as improved hygiene practices and immunisation, for countries with few financial resources.

Coordination (level III)-donors and governments need to jointly prioritise universal access to antimicrobials as a basic step towards achieving universal health coverage. Insufficient access in LMICs is a market failure and requires corrective action, such as the international assistance (both financial and technical) provided through the Global Fund to Fight AIDS, Tuberculosis and Malaria.

Collaborative decisions (level IV)—strengthening of health services and systems to provide universal access to antimicrobials needs to happen at the national level. However, global-level facilitators are needed to ensure affordability in LMICs.

\section{Responsible use in human beings}

Develop mechanisms for responsible marketing, sales, and use

Collaborative decisions (level IV) - although regulations are a national responsibility and prerogative, the global market of antimicrobials crosses many borders. As a result, common standards and practices that are regularly communicated are necessary. These internationally agreed policies could take the form of either self-regulatory codes of practices or a binding legal agreement. Coordination (level III)-although the regulation of medical practice is a core national responsibility, information on best practices for responsible use should be created and shared broadly, with appropriate adjustments showing available resources in the health system.

\section{Responsible use in agriculture}

Restrict specific classes of antimicrobials to human use only

Collaborative decisions (level IV) or collective action (level V)—each country will need to pass effective laws to implement these restrictions. In the short term, incentives could be given to patent holders and generic-drug producers, rewarding them for sales restriction. Global enforcement of this policy necessitates either collaborative decisions or collective action. This policy will only be successful if it is consistently implemented and regulated worldwide.

Reduce the use of antibiotics Collaborative decisions (level IV) or collective action (level V)-although each country needs to determine how it will reduce the for growth promotion and disease prevention in animals use of antibiotics for growth promotion, collaboration is needed to ensure that the reduction is sizeable enough to make a difference and to avoid free riding. Global collective action is probably the best way to avoid free riding in countries where antimicrobial misuse continues. To be effective, compliance incentives or penalty for countries, perhaps through a global legal instrument, are necessary.

Innovation

Finance priority $R \& D$ that is stipulated on responsible use provisions

Collaborative decisions (level IV) or collective action (level V) - R\&D costs are larger than those bearable by any one country, but substantial progress could be made with leadership from groups such as the G7, G20, and BRICS. Collaboration on both financing and R\&D activities is necessary. Usually, financing could be done through governmental coordination (level III); however, the allocation of this financing for new antimicrobials, vaccines, and diagnostics should be bound to restrictions that promote responsible use and therefore require enforcement, meaning that a higher level of collaboration (ie, level IV or V) is necessary. New business models that delink innovation from the volume of sales and unit prices might necessitate collective action, at least by a core group of countries that bear the major share of R\&D costs.

Since we have selected what we believe is the minimum level to drive change, higher levels could also be adopted and be just as successful. FAO=Food and Agriculture Organization. OIE=World Organisation for Animal Health. LMICs=low-income and middle-income countries. R\&D=research and development. BRICS=Brazil, Russia, India, China, and South Africa.

Table 1: Policies that require international collaboration

infection prevention measures than to create new drugs that are short-lived. Evidence of effective infection control interventions is a global public good and should be made readily available, including summaries appropriate for policy makers. ${ }^{4}$

\section{Universal access}

Securing access to quality-assured antimicrobials is a core national responsibility, and policies that countries can use to improve access are discussed by Mendelson and colleagues in this Lancet Series. ${ }^{3}$ The coordinated 
efforts of organisations such as The Global Fund to Fight AIDS, Tuberculosis and Malaria, Unitaid, and the US President's Emergency Plan for AIDS Relief (PEPFAR) have greatly contributed to improved access to specific antimicrobials. However, antibiotics, diagnostics, and related prevention measures mostly fall outside the mandate of these organisations. Most first-line antibiotics are inexpensive, costing only pennies per treatment regimen. However, with the emergence of resistance, the cost ramps up substantially as second-line and third-line drugs are needed. ${ }^{14}$ Donors and governments need to prioritise universal access to affordable and effective antimicrobials as a key part of a comprehensive global solution, thereby contributing to progress towards universal health coverage.

Many untested alternatives to tackle the issue of antimicrobial access will need to be carefully balanced against economic incentives for innovation. One option is for manufacturers to sell their products globally at cost price while receiving rewards (eg, so-called benchmark payments) from high-income countries. These payments would not be tied to unit sales but to compliance with stipulations such as no promotional marketing of the product, sales levels in compliance with responsible use estimates in both human and animal populations, and equitable access. Another option could be that manufacturers offer nominal-royalty-bearing licences to other manufacturers in LMICs, with similar conditions on the licensees. A third option is to establish internationally agreed principles related to securing affordability in low-income countries, where price levels should be based on what can be achieved by competitive manufacturing. All of these options will need decisions that are made in collaboration across countries, with substantial financial support to promote universal access.

\section{Responsible use in and for human beings}

Most countries have regulations to ensure drug quality and responsible marketing, sales, prescriptions, and use of pharmaceuticals. In paper 4 of this Series, Dar and colleagues ${ }^{4}$ have provided specific examples of how these regulations can be strengthened and incentives aligned, including solutions targeting prescribers and reducing over-the-counter sales. However, an international consensus is needed to sustain the global effectiveness of antimicrobials. A potential solution for responsible marketing and sales is a voluntary, self-regulatory code of practice by all manufacturers to restrict marketing and provide transparency on sales and consumption. If such an international self-regulatory mechanism fails, then intergovernmental agreements might be necessary. However, this approach addresses only one side of the issue. At the same time, physicians should be incentivised to adhere to clinical guidelines. Regulations and systems should be strengthened to reduce or eliminate over-the-counter sales without evidence of appropriate diagnosis. The existence of over-the-counter antibiotics is justifiable only as a short-term solution in low-income settings with poor access to health-care professionals or others who could guide responsible use. Ensuring access to effective antimicrobials, like most other health priorities, requires a functioning health-care system.

To change professional behaviour, best practices in the prescribing and use of antimicrobials should be easily and freely accessible worldwide. Although these practices, rooted in evidence and surveillance data, are global public goods, they are time-consuming and expensive to create and disseminate. This is not to say that global guidelines on antimicrobial use are desirable; rather, adjustments need to be made for the national epidemiological context and resistance profile. However, global guidance for best practice guidelines should be coordinated with full transparency.

Some antimicrobials are so medically important that strong actions such as enforcement mechanisms need to be taken to ensure their continued effectiveness. One example is possible limits on over-the-counter sales of critical classes such as carbapenems. For these drugs, an option is to learn from the positive experiences (and avoid the negative results such as those related to challenges to access) of the controlled drug regimen, which is rooted in international treaty commitments. ${ }^{15,16}$ More analyses are needed to explore what aspects of such an approach can be adopted and what aspects will need adaptation.

\section{Responsible use in agriculture}

Antibiotics are important in treatment of disease in both human beings and animals, but they are also being used in healthy animals as growth promoters and a substitute for good animal husbandry. ${ }^{1,4}$ In view of the devastating potential of antimicrobial resistance, all unnecessary use needs to be curbed. FAO, OIE, and WHO have the responsibility to raise awareness in their respective fields regarding maintenance of effective antimicrobials, with WHO having the primary mandate to articulate the public health need for urgent and sustained action. A need exists for a global agreement on responsible animal use by elimination of antibiotics used as growth promoters or as a routine prevention tool through herd treatment. Global collaboration and enforcement are necessary to ensure a level playing field, since reductions in access to antimicrobials might have implications on the running costs of a farm-eg, more oversight of livestock might be needed. ${ }^{1}$ Europe banned the use of antibiotics for growth promotion in 2006. ${ }^{17}$ The USA introduced non-compulsory measures in 2013, which have now resulted in binding withdrawals and label changes. ${ }^{18}$ The Chennai declaration aims to achieve an $80 \%$ compliance with the rule that antibiotics used for human treatment will not be used for growth promotion in food animals. ${ }^{19}$ In exchange for these prohibitions, R\&D related to animal-specific solutions, such as vaccines and alternatives to antibiotics as growth 
promoters, should be encouraged. While these agreements are being negotiated and implemented, a medium-term solution could be labelling suggestions to producers that are already adhering to the best practices. These foods could command higher prices, similar to those of organic or local foods. Several major US restaurant chains are already transitioning to use chicken and other meats produced without antibiotics used in human beings. ${ }^{20}$

International trade law can be an obstacle to reduce or eliminate the use of antibiotics as growth promoters or for routine preventive herd treatment, since a formal national requirement to regulate or ban such use of antibiotics might be interpreted as a trade barrier through the World Trade Organization (WTO) rather than a public health measure. ${ }^{21}$ Therefore, WTO and regional trade agreements need to be engaged to ensure that necessary public health regulations related to antimicrobial resistance are respected.

Another option is to restrict medically important antimicrobials to human use only, leaving other classes, such as ionophores, exclusive to agricultural use. For example, to begin the process towards reaching a global consensus, the G20 countries could develop an agreement in which certain classes of new antimicrobials and other related health technologies are restricted for use in either human beings or animals, and incorporate this agreement into future trade agreements. This agreement could be coordinated through the International Conference on Harmonisation of Technical Requirements for Registration of Pharmaceuticals for Human Use (ICH), a collaboration between the pharmaceutical industry and the regulatory authorities of Europe, Japan, and the USA. ${ }^{22}$ A potential result is that pharmaceutical manufacturers and animal feed providers would be less interested to produce an animal variety for the non-participating countries not only for reputational reasons but also for the limited profitability of the remaining markets. Additionally, innovation incentives for companies could be conditioned on compliance with these rules in every country. Once compliance exists in $\mathrm{ICH}$, it could be transitioned to the more comprehensive International Conference of Drug Regulatory Agencies organised by WHO.

\section{Innovation}

Sustainable access to effective antimicrobials requires constant innovation, if only to prevent us from slipping back into a pre-antibiotic era. ${ }^{23}$ The largest multinational financing initiative so far for antimicrobial $R \& D$ is the Innovative Medicines Initiative (IMI), a public-private partnership between the European Union and the European pharmaceutical industry that aims to develop better and safer drugs. Its New Drugs for Bad Bugs (ND4BB) programme has invested more than $€ 600$ million in European antimicrobial R\&D over 7 years, much of which has been targeted at
Gram-negative bacteria. $^{24}$ The European Union's Joint Programming Initiative on Antimicrobial Resistance (JPIAMR) aims to find routes for novel antibiotics and new anti-infectious disease strategies. Their first call, "InnovaResistance", with a total budget of around $€ 14$ million, was launched in January, 2014, and included funding opportunities for optimisation of existing antimicrobials and identification of new bacterial targets and antibiotic compounds. ${ }^{25}$

Several national initiatives are of a magnitude to have a global effect, even though their geographical scope is restricted. An announcement in June, 2014, stated that the $£_{10}$ million Longitude Prize would focus on point-of-care diagnostics, with the creation of a "cost-effective, accurate, rapid and easy-to-use test for bacterial infections". ${ }^{26}$ A similar diagnostic prize proposal was announced by the US Government in September, 2014. ${ }^{27}$ Some countries have also created partnerships with individual pharmaceutical companies; one such example is the 3.5-year collaboration between AstraZeneca and Singapore's Agency for Science, Technology and Research to develop new drugs against Gram-negative bacterial infections. ${ }^{28}$ The Biomedical Advanced Research and Development Authority (BARDA) in the USA has partnered with GlaxoSmithKline (GSK) to develop new antibiotics with a potential of US\$200 million for GSK if milestones are met. ${ }^{29}$ Total funding from the US National Institutes of Health for antibacterial resistance averaged US\$90 million per year in 2013 and 2014.

Although an increasing investment is seen in relevant $R \& D$, present initiatives are still insufficient to ensure the continued development of new antimicrobials, diagnostics, or related technologies. ${ }^{30}$ Most distressingly, these initiatives are not tied to responsible use policies. In particular, the existing $R \& D$ system closely links incentives for $R \& D$ to the potential price and volume of sales of the eventual product. ${ }^{3}$ This system leads to underinvestment in antibiotic research, high eventual prices for new products, and lacklustre company support of antibiotic stewardship. ${ }^{31}$ There is little assurance that the new drugs will not be wasted through inappropriate use. This market failure could be addressed by efforts to delink company profits from the sales volume for antimicrobials. ${ }^{30}$ Since it is a problem that affects all countries, including those with the financial means to fix it, it should be solvable. Complete global action is not necessarily required because the actions of a few high-income countries can have a disproportionately large global effect, and additional countries will join the effort in due course.

Therefore, a pledge from a group such as the G20 to increase their investment in R\&D tied to responsible use and global access stipulations could have a substantial effect on the antimicrobial R\&D landscape. The new products should be tied to responsible use provisions to minimise the development of resistance, ${ }^{32}$ 


\begin{tabular}{|c|c|c|c|}
\hline & Subobjective & National level & Global level \\
\hline \multicolumn{4}{|l|}{ Access } \\
\hline Expand access & $\begin{array}{l}\text { Increase availability, } \\
\text { affordability, and } \\
\text { diagnostic targeting of } \\
\text { effective antimicrobials }\end{array}$ & $\begin{array}{l}\text { To achieve appropriate antimicrobial prescribing, LMICs should expand access } \\
\text { to appropriate antimicrobials, especially in rural areas, including provision of } \\
\text { laboratory support and increased access to diagnostics }\end{array}$ & $\begin{array}{l}\text { Global universal access demands a long-term commitment, } \\
\text { with sustained financing for all affected countries }\end{array}$ \\
\hline \multicolumn{4}{|l|}{ Responsible use } \\
\hline $\begin{array}{l}\text { Reduce inappropriate } \\
\text { use }\end{array}$ & $\begin{array}{l}\text { Change professional } \\
\text { behaviour }\end{array}$ & $\begin{array}{l}\text { Stewardship programmes can be effective in encouraging appropriate use of } \\
\text { antibiotics and should be scaled up in both HICs and LMICs where feasible }\end{array}$ & $\begin{array}{l}\text { Global guidance should be rooted in evidence and } \\
\text { surveillance data as templates for adaptive national } \\
\text { guidelines on antimicrobial use }\end{array}$ \\
\hline $\begin{array}{l}\text { Increase public } \\
\text { awareness }\end{array}$ & Change public expectations & $\begin{array}{l}\text { Public awareness campaigns can be effective when sustained and properly } \\
\text { adapted for local contexts; national campaigns should be encouraged }\end{array}$ & $\begin{array}{l}\text { Global campaigns should be evidence based and their } \\
\text { results assessed }\end{array}$ \\
\hline $\begin{array}{l}\text { Reduce inappropriate } \\
\text { use in animals }\end{array}$ & $\begin{array}{l}\text { Regulate inappropriate use } \\
\text { or incentivise appropriate } \\
\text { use }\end{array}$ & $\begin{array}{l}\text { Antibiotic use for growth promotion or prophylaxis in animals should be } \\
\text { reduced or eliminated; these policies should be coupled with adequate } \\
\text { investment in improved IPCIs in livestock and for other agricultural uses, and } \\
\text { with effective mechanisms to remunerate veterinarians and prescribers while } \\
\text { limiting their ability to profit from antimicrobial sales and reorienting their } \\
\text { roles away from commercial gains; further research into the implications of } \\
\text { this policy in LMICs is needed }\end{array}$ & $\begin{array}{l}\text { A coalition of key countries can lead the way to restrict } \\
\text { specific classes of antimicrobials for human use only; } \\
\text { countries should work with WTO to transition away from } \\
\text { the use of antibiotics for growth promotion or prophylaxis, } \\
\text { using health and SPS exceptions under trade agreements }\end{array}$ \\
\hline \multicolumn{4}{|l|}{ Infection control } \\
\hline $\begin{array}{l}\text { Reduce need for } \\
\text { antimicrobials }\end{array}$ & $\begin{array}{l}\text { Strengthen infection } \\
\text { control }\end{array}$ & $\begin{array}{l}\text { Implementation of effective IPCls needs to be supported, including } \\
\text { vaccinations, hand hygiene, improved access to water and sanitation, food } \\
\text { safety, and behaviour change }\end{array}$ & $\begin{array}{l}\text { IPCIs have chronic underfunding, particularly in the animal } \\
\text { sector, and an investment of several billion US dollars per } \\
\text { year is necessary to upgrade capacity in most LMICs; } \\
\text { global standards for reporting of infections and training of } \\
\text { health workers on hand hygiene and infection control } \\
\text { should be introduced }\end{array}$ \\
\hline \multicolumn{4}{|l|}{ Innovation } \\
\hline New knowledge (R\&D) & $\begin{array}{l}\text { New antibiotics, } \\
\text { diagnostics, vaccines, and } \\
\text { other relevant technologies }\end{array}$ & $\begin{array}{l}\text { National policies should work in concert with global framework efforts, as } \\
\text { antibiotic R\&D is a global endeavour }\end{array}$ & $\begin{array}{l}\text { A coalition of key countries can initiate efforts that will } \\
\text { have global results, but investments in new antibiotics } \\
\text { should decouple the price from units consumed, so that } \\
\text { responsible use can be built into the reimbursement and } \\
\text { use of diagnostics }\end{array}$ \\
\hline New knowledge (R\&D) & $\begin{array}{l}\text { Increased innovation to } \\
\text { meet the needs of LMICs }\end{array}$ & $\begin{array}{l}\text { National-level research is needed to understand the particular needs of LMICs } \\
\text { with regards to bacterial resistance, such as a rapid point-of-care diagnostic } \\
\text { test that can improve clinical practice in low-resource settings }\end{array}$ & $\begin{array}{l}\text { For antimicrobials, the general recommendations } \\
\text { (including delinkage) of WHO's Consultative Expert } \\
\text { Working Group on Research and Development: Financing } \\
\text { and Coordination should be acted on }\end{array}$ \\
\hline \multicolumn{4}{|l|}{ Surveillance } \\
\hline Improved monitoring & $\begin{array}{l}\text { Infections and outcomes, } \\
\text { and antimicrobial use; } \\
\text { environmental } \\
\text { surveillance; drug quality }\end{array}$ & $\begin{array}{l}\text { Countries and regions should adopt surveillance systems that best suit their } \\
\text { needs and circumstances, and a programme of harmonisation and } \\
\text { integration of global systems needs to be fostered so between-country } \\
\text { comparisons of antibiotic use and resistance can be more meaningful; the } \\
\text { sentinel surveillance of environmental settings that are likely to contribute to } \\
\text { resistance should be initiated and expanded in HICs and its feasibility } \\
\text { explored in LMICs; for LMICs, an additional focus is to improve monitoring of } \\
\text { drug quality to curb the production of substandard and counterfeit drugs }\end{array}$ & $\begin{array}{l}\text { Establish a global surveillance system to annually obtain } \\
\text { data for and report on the use of antimicrobials and the } \\
\text { prevalence of resistance by country, including efforts to } \\
\text { strengthen laboratory capacity, in both human and animal } \\
\text { populations; LMICs might need financial support in these } \\
\text { pursuits; this will also help with a global threat assessment } \\
\text { of risks from antimicrobial resistance }\end{array}$ \\
\hline \multicolumn{4}{|c|}{ Integration across the policy areas } \\
\hline Evidence base & None & $\begin{array}{l}\text { National research programmes need to address unanswered questions and } \\
\text { research gaps, including how to minimise selection of resistance, secure quality } \\
\text { of existing drugs, effectively reduce the prevalence and transmission of } \\
\text { resistant pathogens, and better understand the basic mechanisms of resistance }\end{array}$ & $\begin{array}{l}\text { Systematic reviews of existing policies are needed across } \\
\text { human, animal, and environmental health and the key } \\
\text { areas of resistance control; a standardised framework for } \\
\text { policy examination should be applied and an open-access } \\
\text { central repository of national, regional, and global policy } \\
\text { case studies and assessment developed }\end{array}$ \\
\hline Coordination & None & Not applicable & $\begin{array}{l}\text { Better global coordination and financing mechanisms are } \\
\text { required-eg, informal country coalitions, a pan-UN } \\
\text { intergovernmental agency, or an international treaty }\end{array}$ \\
\hline
\end{tabular}

LMICs=low-income and middle-income countries. HICs=high-income countries. WTO=World Trade Organization. SPS=sanitary and phytosanitary. IPCIs=infection prevention and control interventions. $R \& D=$ research and development.

Table 2: Overall recommendations for policy interventions

which would probably include agreement by manufacturers to not promote the products in exchange for payments that are not based on unit sales. Moreover, the innovators would need to ensure that their new products are globally available, as discussed in the section on universal access. These stipulations would be negotiated and enforced contractually between innovators and high-income countries. 
The global action plan to combat antimicrobial resistance

In this Lancet Series, we have identified a set of recommendations across the five policy areas both for individual countries and globally (table 2). Each one of these policy recommendations could be implemented individually but might work at cross purposes to each other as we have described. To create an effective and sustainable path forward, these recommendations should be implemented in concert.

At the 68th World Health Assembly in May, 2015, a global action plan to combat antimicrobial resistance was approved by Member States. ${ }^{33}$ This global action plan provides the framework for national plans to combat antimicrobial resistance, in which Member States need to define timelines, targets, and activities, and identify particular areas that need technical support from WHO and other partners. Successful implementation depends on Member States playing their crucial part to fulfil commitments, mobilise funding, implement appropriate surveillance programmes, build and support the necessary infrastructure (eg, laboratories), and introduce and enforce appropriate legislation.

The global action plan also gives WHO a clear mandate, leadership, and coordinating role, since WHO represents a natural platform for global health solutions that require improved communication and coordination among countries, including those of surveillance, infection control, and guidance on stewardship (table 1). ${ }^{3.4}$ Although many of the needed global actions have long been recognised, implementation by Member States, WHO, or other actors has been insufficient. A report from the WHO Secretariat concluded that past World Health Assembly resolutions, reports, and calls for mobilisation have not resulted in widely accepted global actions ${ }^{34}$ This inertia could probably be explained by various reasons-eg, insufficient financing, strong lobbying on behalf of diverse stakeholders, free-riding tendencies, and so on. Progress depends on convincing individual countries of the effect of local actions, and finding suitable solutions and the necessary support in this endeavour. ${ }^{3,4}$

\section{National accountability and indicators}

The great differentiator between the global action plan and past WHO resolutions has to be strong national accountability mechanisms to ensure that Member States create and implement their own plans to combat antimicrobial resistance. These mechanisms are likely to be a mixture of incentives and enforcement measures based on measurable indicators. For LMICs, external financing might be predicated upon development of a national plan to combat antimicrobial resistance and eventually report against a set of agreed indicators. Compliance to national plans can be reinforced by widely reporting results in plain language so that local media is engaged in national progress (see table 3 for examples of national indicators).

WHO's South-East Asia Region is to be commended for developing its own indicators in 2010. ${ }^{35}$ Whereas this policy-oriented approach uses process indicators, we suggest data-driven targets, such as annual per-person antibiotic consumption, so that the indicators do not need to change when new national goals are proposed. Almost all of our suggested indicators (table 3) report against several policy areas. For example, annual per-person antibiotic consumption can report progress both in a country with insufficient access to antibiotics and in a country with overuse of antibiotics, showing that interlinkages exist between the policy areas.

Even though we suggest only six indicators, we believe that few countries can report on all six of them at present. Improved surveillance systems will need to be implemented; although such systems are costly and time-consuming, they are a precondition to establish accountability. For low-income countries, such systems

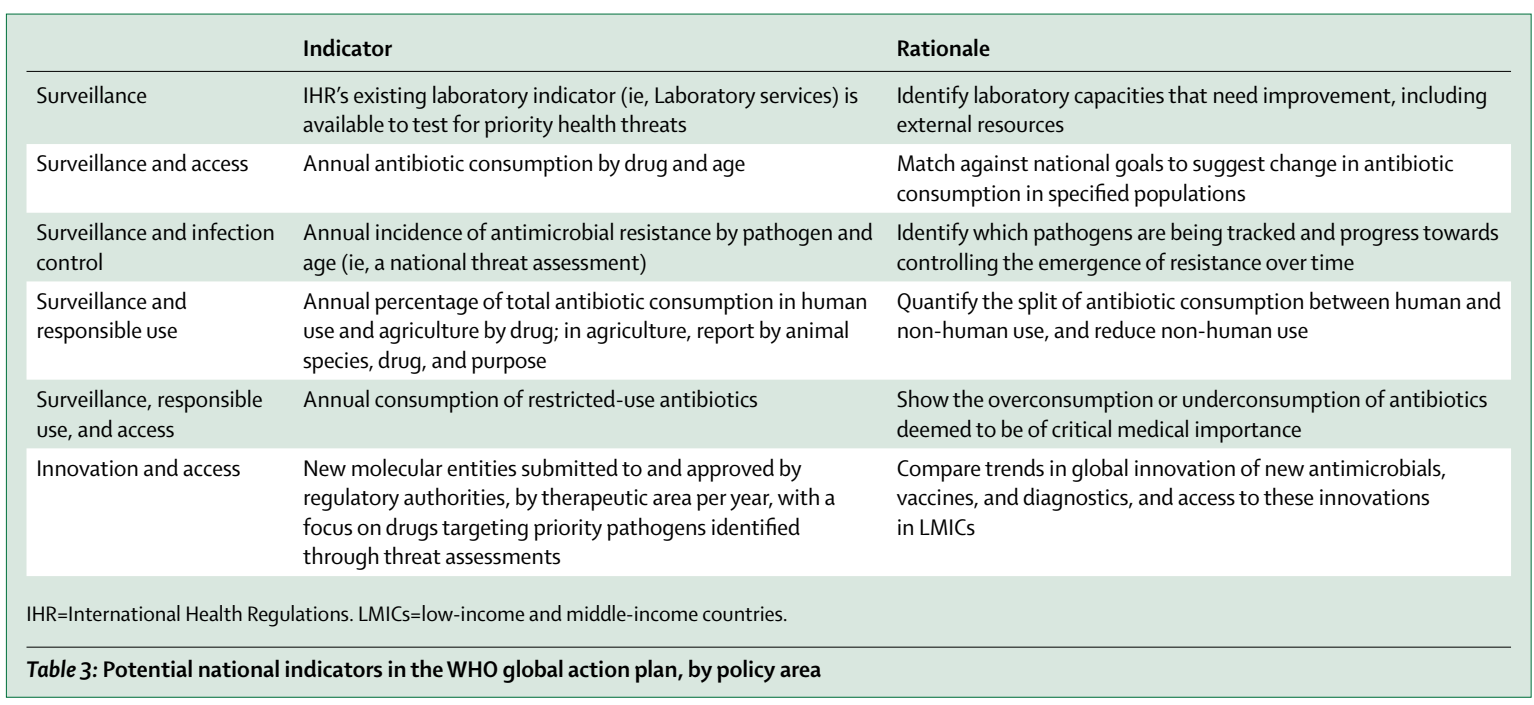




\begin{tabular}{|c|c|c|}
\hline & Benefits & Costs \\
\hline All countries & $\begin{array}{l}\text { Greatly improved global health; avoidance of the costs of a } \\
\text { post-antimicrobial era (eg, inability to perform routine } \\
\text { surgeries and treat common infections); avoidance of the } \\
\text { inevitable closure of borders and restraints on travel and } \\
\text { trade that would follow from rampant epidemics }\end{array}$ & $\begin{array}{l}\text { Increased investments to protect and sustain } \\
\text { effectiveness of antimicrobials }\end{array}$ \\
\hline LMICs & $\begin{array}{l}\text { Enhanced access to affordable antimicrobials, including } \\
\text { subsidised prices when necessary; financial and technical } \\
\text { support for capacity strengthening in surveillance, } \\
\text { responsible use, and infection control }\end{array}$ & $\begin{array}{l}\text { Increased investments in health system capacities for } \\
\text { surveillance, responsible use, and infection control }\end{array}$ \\
\hline Emerging economies & Increased markets for producers of antimicrobials & $\begin{array}{l}\text { Increased investments in and enforcement of regulatory } \\
\text { capacities, and investments in health system capacities } \\
\text { for surveillance, responsible use, and infection control }\end{array}$ \\
\hline High-income countries & $\begin{array}{l}\text { Sustainability of existing antimicrobials and the medical } \\
\text { care system that depends on them }\end{array}$ & $\begin{array}{l}\text { Increased investments in innovation through R\&D and } \\
\text { aggregate reimbursement or delinked payments to } \\
\text { producers; support to LMICs for capacity building }\end{array}$ \\
\hline $\begin{array}{l}\text { Innovative pharmaceutical } \\
\text { companies }\end{array}$ & $\begin{array}{l}\text { Increased rewards and incentives for innovation; decreased } \\
\text { marketing expenses; reduced risk and structured rewards } \\
\text { through delinked payments }\end{array}$ & $\begin{array}{l}\text { Adherence to additional marketing regulations and } \\
\text { cooperation on global public health goals }\end{array}$ \\
\hline Generic pharmaceutical companies & $\begin{array}{l}\text { Opportunity to manufacture antimicrobials on licence } \\
\text { for LMICs }\end{array}$ & $\begin{array}{l}\text { Adherence to additional marketing regulations, quality } \\
\text { assurance, and other stipulations }\end{array}$ \\
\hline Agriculture & $\begin{array}{l}\text { A level playing field with global regulations regarding } \\
\text { antibiotic use in agriculture, especially for meat production }\end{array}$ & $\begin{array}{l}\text { Increased investments in animal health and welfare, } \\
\text { including alternatives to antibiotics }\end{array}$ \\
\hline \multicolumn{3}{|c|}{ R\&D=research and development. LMICs=low-income and middle-income countries. } \\
\hline
\end{tabular}

might require long-term financing commitments from donors, tied to measurable results and careful incremental and scalable implementation, potentially starting first with public hospitals and clinics and expanding from there.

\section{A coherent package of solutions}

These interlinkages between policy areas complicate implementation, since each of the areas requires real effort for some actors, thereby blocking unanimous support. In other cases, benefits for individual groups of actors are insufficient to warrant unilateral action. Among the five policy areas considered in this Series, we have shown that three-namely, access, responsible use, and innovation-will need collaborative global decisions or collective global action (table 1). We believe that the best way forward towards an international agreement on these three policy areas is not to tackle them independently but as one coherent package. These policy areas should be linked to deliver a sustainable and cost-effective solution-eg, by substantially increased coordination of public sector R\&D funding and incentives for innovation, both tied to stipulations of minimal marketing and to licensing intellectual property to manufacturers in LMICs who are also bound by responsible use provisions.

If the coherent package is constructed carefully, most of the diverse range of stakeholders will benefit from a long-term solution securing effective antimicrobials (table 4). High-income countries will need to pay most of the innovation bill but will, in return, protect their populations from infections that cross borders. More equitable access will be achieved for all countries in return for better infection control and stewardship. Low-income countries will get support for capacity building and be assured affordable and appropriate antimicrobials. R\&D-based pharmaceutical companies will receive higher and more predictable rewards for antimicrobial innovations than they do at present, and generic-drug manufacturers will have opportunities to produce quality-assured drugs under licence. Restrictions in antibiotic use in agriculture will promote global fair competition, since all producers have to abide by the same public health measures, supported by research for alternatives to agricultural antibiotics.

\section{Achieving collective action}

The responsibility to implement this coherent package needs to rest on sufficiently funded and empowered authorities. An institutional base and a forum for negotiation are necessary to ensure progress. WHO alone will be unable to facilitate the implementation of this package, and a multisectoral response-eg, from a UN-appointed entity or one structured through a coalition of like-minded, proactive countries and actorswill be essential. Such a response can be rooted in international law or be an institutional solution originating from a top-level political declaration. An internationally binding agreement could be the end result after substantial momentum is achieved in national implementation.

An international legal mechanism can be negotiated at WHO or the UN General Assembly. One weakness of a treaty is the need to cover most or all nations through an 
opt-in instrument that needs ratification by Member States to become legally binding. If WHO is used as a forum, another option is to take advantage of its constitutional power to adopt regulations under Article 21. Such regulations are opt-out instruments that come into force immediately for all Member States after their adoption by the World Health Assembly. ${ }^{36}$ Any legal mechanism at WHO should be paired with a sister agreement at the FAO and OIE to ensure compatibility across sectors.

An international agreement can also be negotiated by a subset of countries and then gradually adopted through incremental processes, such as the Anti-Personnel Mine Ban Convention and the Convention on Cluster Munitions. The advantage of starting with a small group of countries and then expanding is that the process can be swifter, more decisive, and of lower risk than if many countries are involved. ${ }^{36}$ Once a critical mass of countries has signed on, universal agreement can be sought as discussed previously.

An international legal mechanism can contain provisions for technical and financial support for capacity building. One example is the Multilateral Fund for the Implementation of the Montreal Protocol, which assists LMICs to implement measures protecting the ozone layer. ${ }^{37}$ However, it would be difficult for an international legal mechanism itself to mandate binding financial obligations representing large innovation investments, as shown in debates surrounding the financing of $R \& D$ for neglected diseases. ${ }^{38}$ Perhaps lessons can be learnt from international scientific collaborations such as the European Organization for Nuclear Research and the International Space Station.

Another possibility other than a legally binding instrument would be to create a UN agency, similar to UNAIDS, that is mandated with implementation of the coherent package. Led by high-level individuals, this agency could work through the political process and media to elucidate and persuade governments, health professionals, and the public, in a similar process to the Millennium Development Goals, but with a more formal organisational structure. This agency could work with partners such as GAVI Alliance and The Global Fund to Fight AIDS, Tuberculosis and Malaria to implement a plan of expanded appropriate access to effective antimicrobials and vaccines to reduce the need for such drugs.

\section{Conclusion}

Interdependent and interconnected problems need integrated solutions. Concurrent expansion of access and reduction of inappropriate use are necessary, and innovation rewards have to be delinked from unit-based sales revenues so that payments are not generally based on the number and price of drugs sold. Securing effective antimicrobials calls for systemic and interdependent solutions. ${ }^{39,40}$
Global public goods, such as new antimicrobials, diagnostics, and treatment guidelines, should be secured through joint contributions and collaboration. Mobilisation of global solidarity will be necessary to secure resources and financing for universal access and for national capacities for surveillance, responsible use, and infection control. Coordination of these functions will require not only leadership and political will, but also strong implementation and potentially enforcement mechanisms. ${ }^{41}$

Fortunately, securing effective antimicrobials has finally gained a place on the global agenda. Member States have endorsed WHO's global action plan to combat antimicrobial resistance. ${ }^{42}$ The USA has launched a national strategy and an action plan to address antibiotic resistance, which awaits Congressional action. ${ }^{43}$ The Transatlantic Task Force on Antimicrobial Resistance between the USA and the European Union has put forward a series of recommendations for joint action. $^{23}$ South Africa has agreed to an antimicrobial resistance national strategy framework. ${ }^{44}$ The UK has initiated an independent review on antimicrobial resistance, which stated that development of ten new highly effective drugs in the next decade would cost less than US $\$ 25$ billion (or $0.03 \%$ of global gross domestic product [GDP]). ${ }^{45,46} \mathrm{~A}$ recent report to the Nordic Council of Ministers ${ }^{47}$ recommended a global investment of $0.005 \%$ of annual global GDP over a 5 -year period. There has also been a call for an intergovernmental antimicrobial panel, like the UN Intergovernmental Panel on Climate Change, which can synthesise and organise the available evidence to inform adoption and implementation of national policies. ${ }^{48}$ However, such a panel might be unnecessary, since a scientific consensus has already been reached regarding actions needed to secure effective antimicrobials.

Global actions need to integrate access to effective antimicrobials with infection prevention, responsible use of existing antimicrobials, surveillance, and innovation. These actions need to bridge the realms of public health, agriculture, animal husbandry, and trade. We have proposed a set of national and global recommendations (table 2) rooted in the analyses of this Lancet Series. ${ }^{1-4}$ Recommendations should be supported by strong implementation mechanisms that incorporate incentives for leaders to act on them, institutions that bring edicts into effect, and interests advocating their prioritisation. ${ }^{36,49}$ This implementation should lead to a new global institutional arrangement, either an international legal mechanism or a UN agency.

Deadly bacterial pathogens are present in every country of the world, and new resistant pathogens are evolving every day. We need to secure and expand our arsenal of antimicrobials. Therefore, we urge world leaders to consider, commit to, and champion implementation of these recommendations. 


\section{Contributors}

$\mathrm{CA}, \mathrm{KO}, \mathrm{SJH}$, and J-AR conceived and designed the manuscript, including the section on policy synthesis. All authors reviewed and edited the entire article, and approved the final submitted version.

\section{Declaration of interests}

We declare no competing interests.

\section{Acknowledgments}

There was no funding to write this manuscript. However, travel and accommodation to attend author meetings were paid jointly by the Center for Disease Dynamics, Economics \& Policy and the Norwegian Institute of Public Health. SJH is financially supported by the Canadian Institutes of Health Research, Research Council of Norway, and the Trudeau Foundation. The opinions expressed are those of the authors and do not reflect the views of any of the authors' institutions.

\section{References}

1 Laxminarayan R, Matsoso P, Klugman KP, et al. Access to effective antimicrobials: a worldwide challenge. Lancet 2015; published online Nov 18. http://dx.doi.org/10.1016/S0140-6736(15)00474-2.

2 Holmes AH, Moore LSP, Sundsfjord A, et al. Understanding the mechanisms and drivers of antimicrobial resistance. Lancet 2015; published online Nov 18. http://dx.doi.org/10.1016/S0140 6736(15)00473-0

3 Mendelson M, Røttingen J-A, Gopinathan U, et al. Maximising access to achieve appropriate human antimicrobial use in lowincome and middle-income countries. Lancet 2015; published online Nov 18. http://dx.doi.org/10.1016/S0140-6736(15)00547-4.

4 Dar OA, Hasan R, Schlundt J, et al. Exploring the evidence base for national and regional policy interventions to combat resistance. Lancet 2015; published online Nov 18. http://dx.doi.org/10.1016/ S0140-6736(15)00520-6

5 Hoffman S, Outterson K, Røttingen J-A, et al. An international legal framework to address antimicrobial resistance. Bull World Health Organ 2015; 93: 66.

6 Health Professions Network Nursing and Midwifery Office within the Department of Human Resources for Health. Framework for action on interprofessional education and collaborative practice. Geneva: World Health Organization, 2010. http://apps.who.int/iris/ bitstream/10665/70185/1/WHO_HRH_HPN_10.3_eng.pdf (accessed Sept 22, 2015).

7 WHO. WHA51.17-Emerging and other communicable diseases: antimicrobial resistance. Geneva: World Health Organization, 1998. http://apps.who.int/medicinedocs/documents/s16334e/s16334e.pdf (accessed Sept 22, 2015).

8 WHO. WHO global strategy for containment of antimicrobia resistance. Geneva: World Health Organization, 2001. http://www. who.int/drugresistance/WHO_Global_Strategy_English.pdf (accessed Sept 22, 2015).

9 WHO. Antimicrobial resistance: global report on surveillance, 2014 Geneva: World Health Organization, 2014. http://www.who.int/ drugresistance/documents/surveillancereport/en/ (accessed Sept 22, 2015)

10 WHO. International Health Regulations (2005), 2nd edn. Geneva: World Health Organization, 2008. http://apps.who.int/iris/ bitstream/10665/43883/1/9789241580410_eng.pdf (accessed Sept 22, 2015)

11 World Health Organization. EB134/32-Implementation of the International Health Regulations (2005). Geneva: World Health Organization, 2013. http://apps.who.int/gb/ebwha/pdf_files/ EB134/B134_32-en.pdf (accessed Sept 22, 2015).

12 Food and Agriculture Organization, World Health Organization, World Organisation for Animal Health. Strengthening laboratory capacity in response to emerging pandemic threats: FAO, OIE and WHO working together. 2011. https://www.usaid.gov/sites/ default/files/documents/1864/identify_leaflet.pdf (accessed Sept 22, 2015)

13 Allegranzi B, Bagheri Nejad S, Combescure C, et al. Burden of endemic health-care-associated infection in developing countries: systematic review and meta-analysis. Lancet 2011; 377: 228-41.

14 WHO. Containing antimicrobial resistance-WHO policy perspectives on medicines. Geneva: World Health Organization, 2005. http://www.who.int/management/anmicrobialresistance.pdf (accessed Sept 22, 2015).
15 O’Brien M, Mwangi-Powell F, Adewole IF, et al. Improving access to analgesic drugs for patients with cancer in sub-Saharan Africa. Lancet Oncol 2013; 14: e176-82.

16 Bewley-Taylor D, Jelsma M. Regime change: re-visiting the 1961 Single Convention on Narcotic Drugs. Int J Drug Policy 2012; 23: 72-81.

17 European Commission. Ban on antibiotics as growth promoters in animal feed enters into effect, IP/05/1687. Dec 22, 2005. http://europa. eu/rapid/press-release_IP-05-1687_en.htm (accessed Sept 22, 2015).

18 US Food and Drug Administration. Phasing out certain antibiotic use in farm animals. December, 2013. http://www.fda.gov/ ForConsumers/ConsumerUpdates/ucm 378100.htm (accessed Sept 22, 2015)

19 Chennai Declaration Team. "Chennai Declaration": 5-year plan to tackle the challenge of anti-microbial resistance. Indian J Med Microbiol 2014; 32: 221-28.

20 Godoy M. Americans want antibiotic-free chicken, and the industry is listening. National Public Radio. Feb 19, 2014. http://www.npr.org/ sections/thesalt/2014/02/14/276976353/americans-want-antibioticfree-chicken-and-the-industry-is-listening (accessed Sept 22, 2015).

21 Silverglade BA. The WTO agreement on sanitary and phytosanitary measures: weakening food safety regulations to facilitate trade? Food Drug Law J 2000; 55: 517-24.

22 Molzon JA, Giaquinto A, Lindstrom L, et al. The value and benefits of the International Conference on Harmonisation to drug regulatory authorities: advancing harmonization for better public health. Clin Pharmacol Ther 2011; 89: 503-12.

23 Transatlantic Task Force on Antimicrobial Resistance (TATFAR). TATFAR progress report 2014. Atlanta, GA: Centers for Disease Control and Prevention, 2014

24 Innovative Medicines Initiative. New Drugs for Bad Bugs (ND4BB). 2014. http://www.imi.europa.eu/content/nd4bb (accessed Oct 7, 2014).

25 Joint Programming Initiative on Antimicrobial Resistance. The firs JPIAMR transnational call InnovaResistance: innovative approaches to address antibacterial resistance. 2014. http://www.jpiamr.eu/ activities/joint-calls/1st-joint-call/ (accessed July 10, 2014).

26 Nesta. Antibiotics: How can we prevent the rise of resistance to antibiotics? 2014. http://www.longitudeprize.org/challenge/ antibiotics (accessed Dec 8, 2014)

27 The White House. National strategy for combating antibiotic resistant bacteria. Washington, DC: The White House, 2014 https://www.whitehouse.gov/sites/default/files/docs/carb_national_ strategy.pdf (accessed Sept 22, 2015)

28 Grogan K. AstraZeneca antibiotic pact with Singapore's A*Star. PharmaTimes Online. Nov 5, 2013. http://www.pharmatimes.com/ article/13-11-05/AstraZeneca_antibiotic_pact_with_Singapore_s_A_ Star.aspx (accessed Sept 22, 2015)

29 GlaxoSmithKline. GlaxoSmithKline awarded up to $\$ 200$ million by U.S. government to develop new antibiotics. Middlesex: GlaxoSmithKline, 2013.

30 Outterson K. New business models for sustainable antibiotics. London: Royal Institute of International Affairs, 2014. https://www. chathamhouse.org/sites/files/chathamhouse/public/Research/ Global\%20Health/0214SustainableAntibiotics.pdf (accessed Sept 22, 2015).

31 Outterson K, Powers JH, Daniel GW, McClellan MB. Repairing the broken market for antibiotic innovation. Health Aff (Millwood) 2015; 34: $277-85$.

32 Kesselheim AS, Outterson K. Fighting antibiotic resistance: marrying new financial incentives to meeting public health goals. Health Aff (Millwood) 2010; 29: 1689-96.

33 WHO. Global action plan on antimicrobial resistance. Geneva: World Health Organization, 2015. http://www.who.int/ drugresistance/global_action_plan/en/ (accessed Sept 22, 2015).

34 WHO. Sixty-seventh World Health Assembly provisional agenda item 16.5. Antimicrobial drug resistance. Report by the Secretariat, A67/39. Geneva: World Health Organization, 2014. http://apps.who.int/gb/ ebwha/pdf_files/WHA67/A67_39-en.pdf (accessed Sept 22, 2015).

35 WHO Regional Office for South-East Asia. Regional strategy on prevention and containment of antimicrobial resistance. Geneva: World Health Organization, 2010. http://www.searo.who.int/entity/ antimicrobial_resistance/BCT_hlm-407.pdf (accessed Sept 22, 2015)

36 Hoffman SJ, Røttingen J-A. Assessing implementation mechanisms for an international agreement on research and development for health products. Bull World Health Organ 2012; 90: 854-63. 
37 Kelly L. The multilateral fund for the implementation of the Montreal protocol. Washington, DC: The World Bank Operations Evaluation Department, 2004. http://lnweb90.worldbank.org/oed/ oeddoclib.nsf/DocUNIDViewForJavaSearch/1F099B2068ADC1C28 256F640069653D/\$file/gppp_mlf_wp.pdf (accessed Oct 20, 2015).

38 Moon S. WHO's role in the global health system: what can be learned from global R\&D debates? Public Health 2014; 128: 167-72.

39 Frenk J, Moon S. Governance challenges in global health. N Engl J Med 2013; 368: 936-42.

40 Jamison DT, Summers LH, Alleyne G, et al. Global health 2035: a world converging within a generation. Lancet 2013; 382: 1898-955.

41 Hoffman SJ, Røttingen J-A. Assessing the expected impact of global health treaties: evidence from 90 quantitative evaluations. Am J Public Health 2015; 105: 26-40.

42 WHO. WHO 67.25 Antimicrobial resistance. Geneva: World Health Organization, 2014. http://apps.who.int/gb/ebwha/pdf_files/ WHA67/A67_R25-en.pdf (accessed Sept 22, 2015).

43 The White House. National action plan for combating antibioticresistant bacteria. Washington, DC: The White House, 2015. https://www.whitehouse.gov/sites/default/files/docs/national_ action_plan_for_combating_antibotic-resistant_bacteria.pdf (accessed Sept 22, 2015).
44 Republic of South Africa. Antimicrobial Resistance National Strategy Framework Commitments. Johannesburg: Republic of South Africa, 2014.

45 Review on Antimicrobial Resistance. Review on Antimicrobial Resistance, 2014. http://amr-review.org/ (accessed April 21, 2015).

46 O'Neill J. Ten ways to kill our antibiotics complacency. The Times (London), April 21, 2015.

47 Könberg B. The Future Nordic Co-operation on Health. Copenhagen: Nordic Council of Ministers, 2014. http://www. norden.org/en/theme/haallbar-nordisk-vaelfaerd/research-forwelfare/the-future-nordic-co-operation-on-health (accessed Sept 22, 2015).

48 Woolhouse M, Farrar J. Policy: an intergovernmental panel on antimicrobial resistance. Nature 2014; 509: 555-57.

49 Hoffman SJ, Røttingen J-A, Frenk J. Assessing proposals for new global health treaties: an analytic framework. Am J Public Health 2015; 105: 1523-30. 